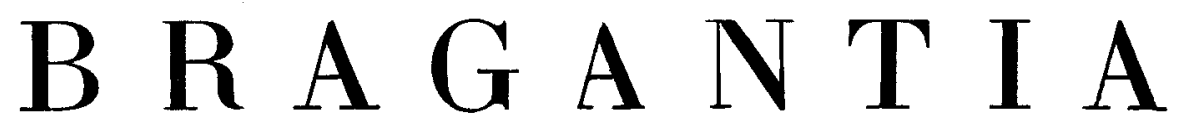

Boletim Cientifico do Instituto Agronômico do Estado de S. Paulo

Vol. 29

Campinas, novembro de 1970

N. ${ }^{\circ} 32$

\title{
VARIAÇÕES SAZONAIS DA MIGRAÇÃO DE Myzus persicae EM CAMPINAS NOS ANOS DE 1967 A 1969 (1)
}

C. L. Costa, engenheiro-agrônomo $(2,3)$, Seção de Virologia, Ins-
tituto Agronômico

\section{SINOPSE}

Para estudar as variações sazonais do número de migrantes de Myzus persicae (Sulz.) em Campinas, foram utilizadas armadilhas de dois tipos, para a sua coleta: a de sucção e a de água.

Fêmeas viviparas, partenogenéticas, aladas, da espécie, foram coletadas em tôdas as semanas durante os anos de 1967,1968 e 1969 . A presença de alguns raros machos foi também regisirada.

A armadilha de água coletou sempre maior número de individuos do que a de sucção, durante todo o período de observações. Entretanto, as curvas que representam as variações semanais e mensais do número de migrantes da espécie, construídas com as amostras obtidas por ambos os tipos de armadilhas, têm a mesma forma. As maiores migrações se aeram nos meses de maío a setembro.

A proporção de exemplares de M. persicae em relação ao total das espécies coletacias foi sempre maior na armadilha de água do que na de sucção.

\section{1 - INTRODUÇÃO}

O papel preponderante das formas aladas dos afídios sôbre as ápteras na transmissão de vírus de plantas para as culturas e geralmente aceito pelos autores desde há muito. A existência

(1) Trabalho parcialmente subvencionado pela Fundação de Amparo à Pesquisa do Estado de Säo Paulo (C. Agron. 65/449) e pelo Banco Nacional do Desenvolvimento Económico (Contrato Fundrepo - 42: Projeto 9). Recebido para publicação em 25 de março de 1970.

( $\left.{ }^{2}\right)$ Bolsista do Conselho Nacional de Pesquisas.

$\left(^{3}\right)$ o autor expressa seus agradecimentos ao Dr. A. S. Costa, Chefe da Seção de virologia, pelas sugestôes oferecidas na discussão e interpretação dos resultados dêst'e trabalho. 
de correlação positiva significativa entre o número de alados capturados em armadilhas e a disseminação de um vírus foi, pela primeira vez, evidenciada por Broadbent em 1950 (2). $O$ virus envolvido era o do enrolamento da fôlha da batatinha, cujo vector principal é o afídio Myzus persicae (Sulz.).

Desde então, nos estudos da epidemiologia das moléstias de vírus de plantas, transmitidas por afídios, tem sido comum 0 emprêgo de armadilhas para determinar as variaçôes nas populações dêste grupo de vectores. Armadilhas de vários tipos têm sido usadas para êste fim, das quais a mais precisa é, sem dúvida, a de sucção, idealizada por Johnson (12) e aperfeiçoada por Taylor (19).

Entre nós, na Seção de Virologia, Instituto Agronômico de Campinas, estão em curso estudos que visam determinar as variações sazonais na população dos principais vectores, bem como investigar a existência de possiveis correlações entre a atividade dêles e a disseminação dos vírus que êles transmitem.

Neste artigo é apresentada a análise dos dados reunidos nos últimos três anos pela coleta contínua de formas aladas de Myzus persicae, o mais importante vector de vírus de plantas em todo o mundo.

\section{2 - MATERIAIS E MÉTODOS}

Armadilhas de dois tipos foram utilizadas na coleta dos insetos: de sucção e de água.

Armadilha de sucção - do tipo descrito por Johnson (12) e Taylor (19) e hoje fabricada indùstrialmente na Inglaterra. Para a sua construção aqui, foi necessário adaptar hélice de ventilador de automóvel DKW-Vemag a um exaustor Walita, modêlo E 122, para conseguir a sucção do ar na direção adequada para o seu funcionamento. Ela não possui o mecanismo de segregação da amostra como nos modelos inglêses. O cilindro coletor foi substituído por um recipiente de plástico, no qual se coloca álcool, glicerina e água, onde os insetos são diretamente coletados (13).

Este recipiente, trocado todos os dias, permite que a amostra obtida represente a coleta correspondente a períodos de 24 horas de operação. Embora as coletas representem estimativas da densidade de afídios no ar (número de alados/volume de 
ar) não é possível indicar numèricamente os seus valores. Isto porque nāo se tem conhecimento do volume de ar succionado pelo exaustor na unidade de tempo, devido à adaptação acima mencionada.

Armadilha de água - baseada no modêlo originalmente descrito por Moericke (14), mas com algumas modificaçōes. Ela consiste, simplesmente, de uma assadeira comum de cozinha, de $34 \times 22 \times 7$ centímetros, pintada internamente com tinta Sherwin Williams, amarelo-cromo, número 105. Numa de suas paredes laterais abre-se uma "janela", à qual cola-se um pedaço de tela de nylon. O nível superior da janela fica a $1 \mathrm{~cm}$ abaixo do bordo do recipiente, de modo a permitir que a água escorra através da tela, evitando que ela venha a transbordar, quando exposta à chuva, o que poderia acarretar perda de insetos. À água contida no recipiente são adicionadas algumas gôtas de detergente líquido, que, agindo como agente molhante, impede que os insetos escapem.

Coleta e separação dos insetos - Neste estudo, os insetos coletados na armadilha de água foram recolhidos diàriamente, exceto aos sábados e domingos; os recipientes da de sucção foram trocados todos os dias.

Os afídios foram separados do total de insetos coletados, e identificados sempre que possível ao nível de gênero e espécie, sob a binocular, anotando-se o número de exemplares de cada um. A espécie Myzus persicae é fàcilmente reconhecida neste exame, ainda que os exemplares não tenham sido clarificados. Eventualmente exemplares coletados, quer na armadilha de sucção, quer na de água, eram remetidos ao "Bristish Museum (Natural History)", em Londres, para terem sua identidade confirmada pelo Dr. V. F. Eastop.

Todos os exemplares coletados foram guardados numa mistura de álcool 95\% ( 2 volumes) e ácido lático $75 \%$ (1 volume) (18), para documentar os resultados.

Ambas as armadilhas estão em operação na esplanada onde se localizam os prédios da Seção de Virologia, em Campinas, sôbre solo limpo. A de sucção suga o ar a 1 metro acima do nivel do solo, continuamente, há dois anos. A de água está apoiada diretamente no solo, coletando insetos desde janeiro de 1967. 


\section{3 - RESULTADOS}

Os diagramas das figuras 1 e 2 mostram os números de alados da espécie Myzus persicae coletados por semana ou mês, em cada um dos três anos, em Campinas. Os valores diários, em geral muito variáveis, não foram considerados para a análise. As semanas correspondentes, em cada ano, náo se iniciaram no mesmo dia. As de 1968 e as de 1967 iniciaram-se, respectivamente, um dia e três dias depois das de 1969. A coleta mensal representa a soma do total de exemplares coletados nas semanas de cada mês.

As temperaturas médias das décadas dos diferentes meses, nos três anos de observações, estão também representadas na figura $1\left({ }^{a}\right)$.

O total de alados de $M$. persicae coletado na armadilha de água foi de 4842 no primeiro ano, 6375 no segundo e 4130 no terceiro. Os números correspondentes para a de sucção foram de 1788 em 1968 e 932 em 1969. A quase totalidade dêles foi representada por fêmeas vivíparas partenogenéticas, tendo sido registrada a presença de alguns raros machos ( 7 ).

Em 1967, sòmente na semana 5 , o número de afídios coletados na armadilha de água foi inferior a 10 exemplares e, na maioria delas, superior a 30 . Entre as semanas 17 e 33 (maio-agôsto) registraram-se as maiores coletas de alados de $M$. persicae. A maior delas ocorreu na semana 22, constituída de 447 exemplares ( $9 \%$ do total anual).

Os maiores valores mensais foram os de maio a agôsto, quando cêrca de $57 \%$ do total anual foi capturado, caindo depois $\Theta$ voltando a se elevar no mês de dezembro, quando foi coletado cêrca de $9 \%$ do total anual. Os totais de março e abril foram também relativamente altos.

Em 1968, sòmente em 7 semanas, a coleta da armadilha de àgua foi inferior a 10 exemplares. $\mathrm{Na}$ de sucção isto ocorreu em 16 semanas. As maiores coletas foram obtidas entre as semanas 19 e 27 (maio-julho), registrando-se o maior valor na semana 25 , quando 764 exemplares ( $12 \%$ do total anual) foram

(a) O autor expressa seus agradecimentos ao Eng.-Agr.o Altino A. Ortolani, da Seçáo de Climatologia Agrícola, déste Instituto, pelos dados de temperaturas incluidos neste artigo. 

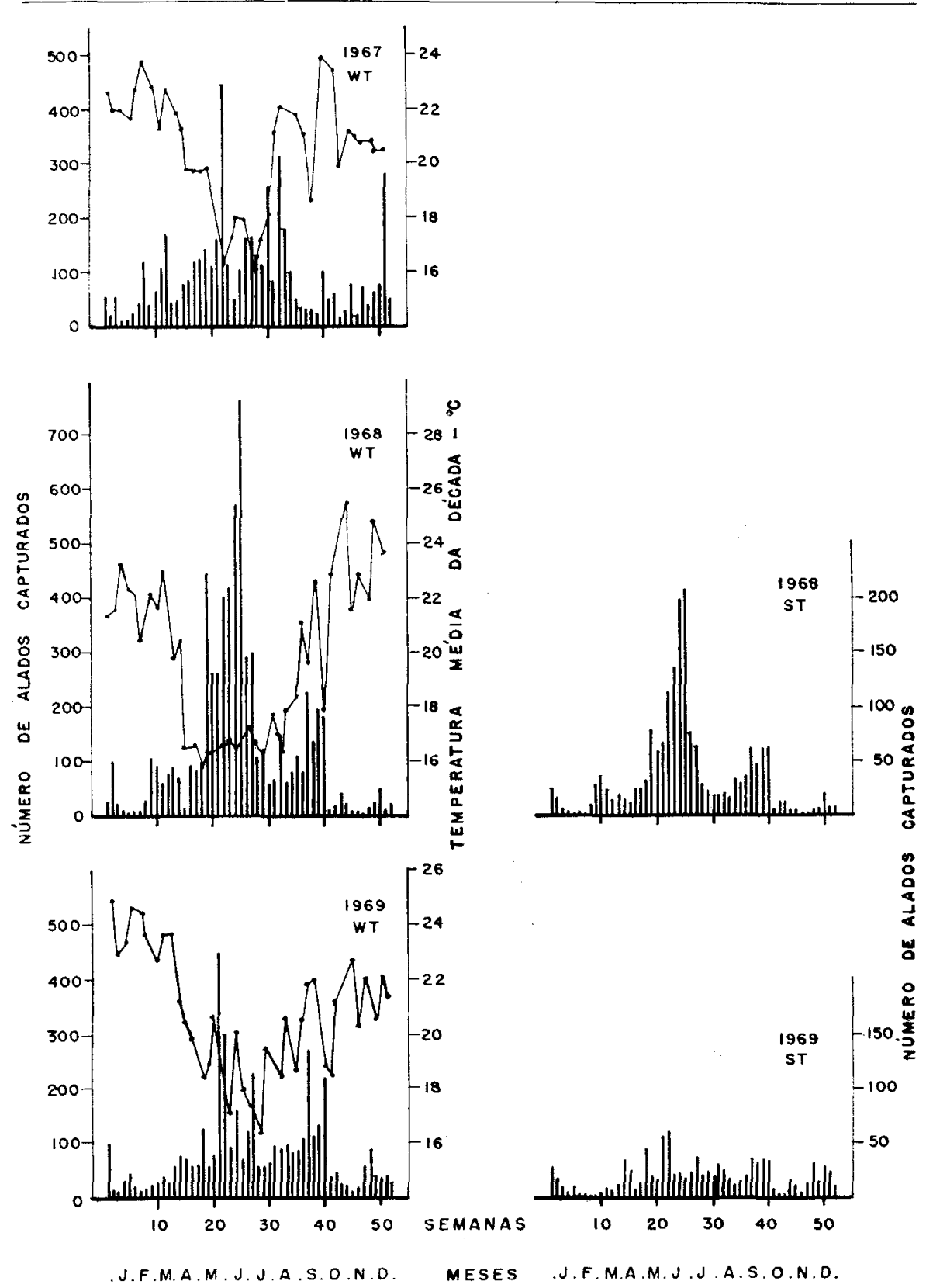

Figura 1. - Comparação das amostras semanais (colunas) de alados de Myzus persicae obtidas em Campinas nos anos de 1967. 1968 e 1969 em uma armadilha de água (WT) e em uma de succáo (ST). Os pontos representam as temperaturas médias das décadas de cada mês 

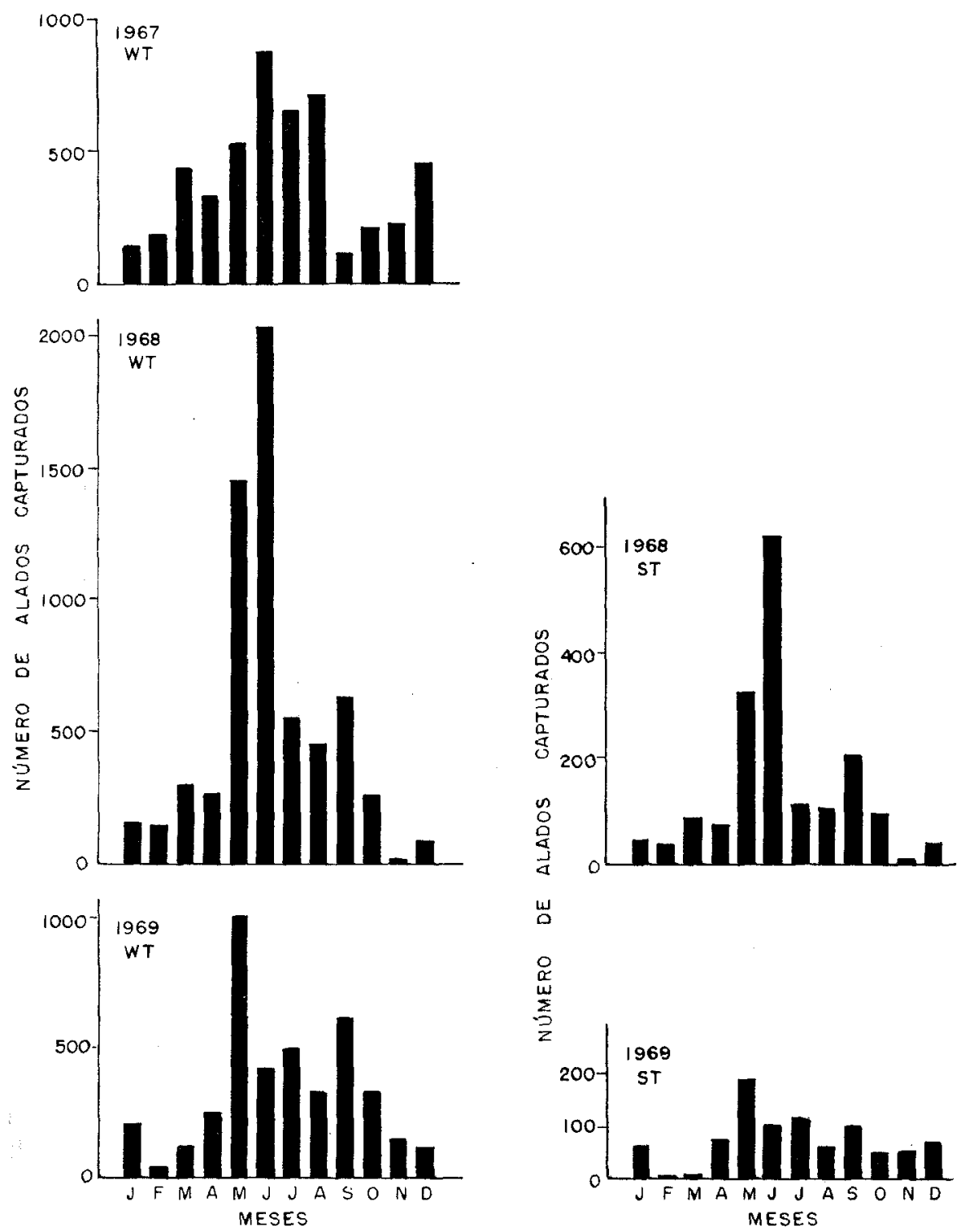

Figura 2. - Comparação das amostras mensals de alados de Myzus persicae obtidas em Campinas, SP, durante os anos de 1967, 1968 e 1969, em armadilha de água (WT) e de sucçãa (ST). 
coletados na de água, e 206 ( $11 \%$ do total anual) na de sucção (figura 1). Nesse período foi coletado cêrca de $58 \%$ do total anual na armadilha de água e $55 \%$ na de sucção. Após êste período houve uma pequena queda no valor das amostras semanais, que voltou a elevar-se nas semanas 37 a 40 .

A existência de um pico em maio-julho pode ser constatada nos diagramas que representam a comparação das amostras mensais obtidas pelas duas armadilhas. As amostras de julho, agôsto e setembro foram as maiores obtidas em seguida às dos meses correspondentes ao pico (figura 2 ).

Em 1969, sòmente em duas semanas, a amostra da armadilha de água continha menos que 10 alados. Na de sucção foram obtidas amostras menores que 10 em 17 ocasiōes. As mais altas coletas foram obtidas entre as semanas 18 e 27 (maio-julho), registrando-se a maior na semana 21 , tendo sido coletados 445 exemplares ( $11 \%$ do total anual) na armadilha de água e 55 ( $6 \%$ do total anual) na de sucção. Neste período a armadilha de água coletou cêrca de $40 \%$ do total anual, e a de sucção, cêrca de $37 \%$. As coletas que se seguiram a êste periodo foram menores, voltando a elevar-se nas semanas 37 a 40 (figura 1 ).

A maior das amostras mensais foi a de maio, quando 1.003 exemplares ( $24 \%$ do total anual) foram coletados na armadilha de água. A de setembro, com 619 exemplares (15\% do total anual), foi a maior obtida em seguida à daquele mês. As amostras de junho e julho foram constituídas de 400 exemplares, e as de agôsto e outubro, de 350. Na armadilha de sucção, a maior foi também a de maio, seguida das amostras dos meses de junho a setembro.

A porcentagem de alados de Myzus persicae em relação ao total de alados das demais espécies de afídios coletadas anualmente na armadilha de água foi de 28\% em 1967, 36\% em 1968 e $28 \%$ em 1969. Para a de sucção os valores correspondentes foram: $15 \%$ em 1968 e $10 \%$ em 1969 . Os valores para cada mês, nos três anos de observações, encontram-se representados gràficamente nos diagramas da figura 3.

Em 1967, a proporção dêste afídio em relação ao total das espécies coletadas se aproximou de $\mathbf{5 0 \%}$ nos meses de fevereiro, março, junho, julho e outubro. Em 1968, a maior proporção 


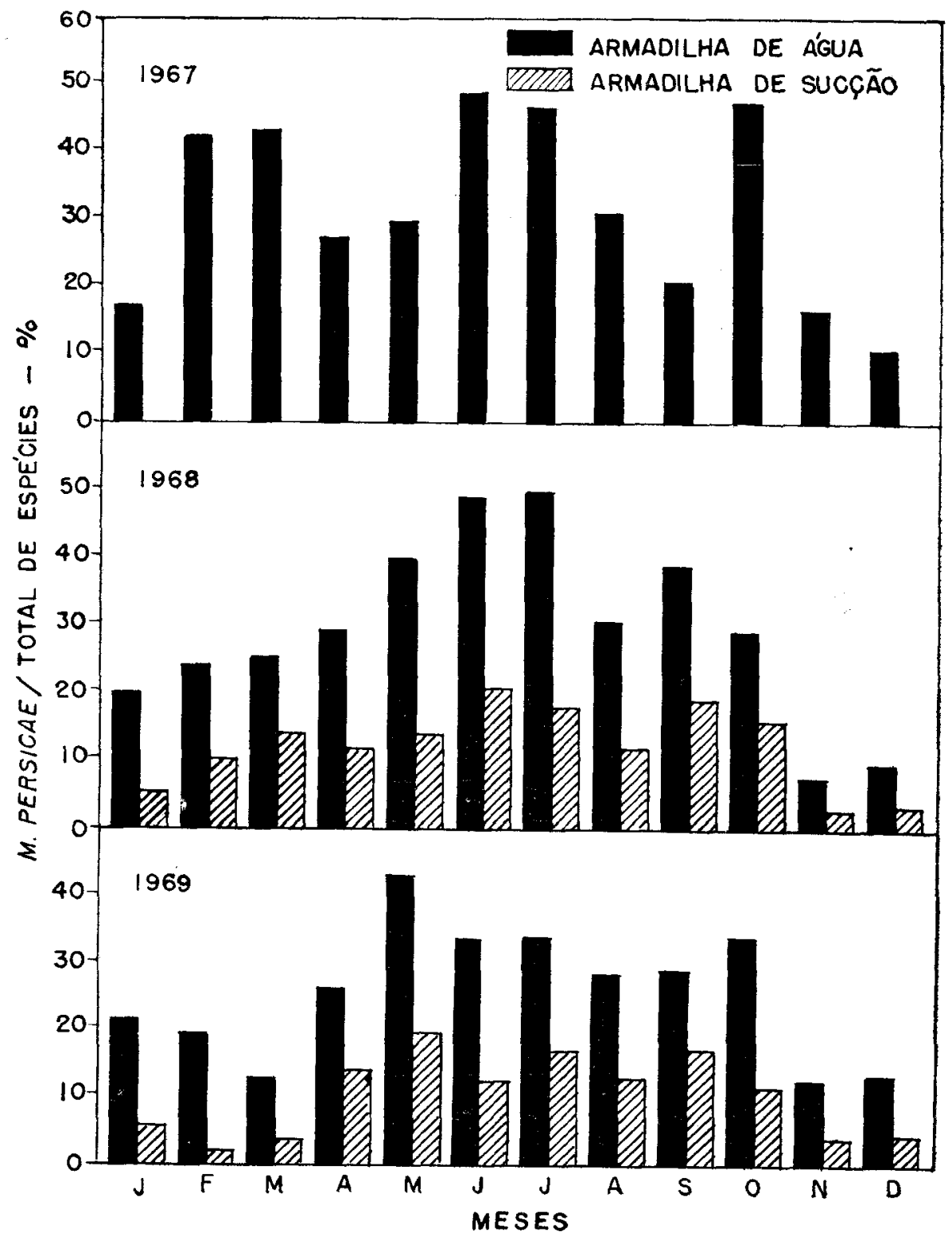

Figura 3. - Porcentagem de alados de Myzus persicae, em relacão ao total de espécies coletadas em cada mês, nos anos de 1967, 1968 e 1969, em Campinas, SP. 
(50\%) desta espécie em relação ao total das espécies coletadas correspondeu aos meses de junho e julho (figura 3). Em 1969 as maiores proporções de Myzus persicae em relação ao total das espécies coletadas foram as dos meses de maio a outubro.

Os valores para a armadilha de sucção foram sempre menores (diagramas da figura 3 ). A proporção de $M$. persicae em relação ao total das espécies coletadas só foi superior a $20 \% \mathrm{em}$ uma ocasião (junho de 1968). Tanto em 1968 como em 1969 ela se manteve ao redor de $15 \%$ nos meses de maio a outubro.

\section{4 - DISCUSSÃO}

Os dados obtidos mostram que a atividade de Myzus persicae não sofreu interrupção em nenhuma semana, durante os três anos de observações. Aparentemente não houve fatôres desfavoráveis, para limitar o desenvolvimento e inibir o vôo dessa espécie em Campinas, no período estudado. As variaçōes observadas na população de migrantes da espécie, conquanto tenham alcançado certa extensão, não se comparam com as verificadas em paises de inverno mais rigoroso, onde a atividade do afídio se restringe a um determinado período do ano.

A captura de fêmeas vivíparas, partenogenéticas, em tôđas as semanas dos três anos de observações é evidência de que, nas nossas condições, a espécie tem possibilidades de multiplicar-se continuadamente por via assexuada. A coleta de alguns machos nas armadilhas põe em relêvo a possibilidade de, durante os meses mais frios do ano, desenvolver-se nas hospedeiras primárias ( Prunus spp.) (17) populações sexuadas da espécie. O autor não tem conhecimento da ocorrência, na região de Campinas, de fêmeas oviparas ou outra qualquer das formas do afídio associadas à sua multiplicação por via sexuada.

Embora a armadilha de água tenha coletado sempre maior número de individuos do que a de sucção, as curvas que representam as variaçōes na população de migrantes da espécie, avaliadas pelas coletas de ambos os tipos de armadilhas, têm a mesma configuração. Isto mostra que a armadilha de água, mesmo exercendo atração para os afídios, forneceu uma medida da variação da população de migrantes no ar proporcional à estimativa da densidade obtida pela de sucção, aparelho mais preciso, cujo princípio de funcionamento não inclui a atração (20). Dêsse modo, as armadilhas de água poderão ser usadas, com vanta- 
gens, na coleta de Myzus persicae, onde não haja disponibilidade de energia elétrica exigida para o funcionamento das de sucção e nas ocasióes de baixa densidade de alados no ar. Elas devem ser colocadas sempre sôbre o mesmo "background", para fornecerem amostras comparáveis, pois acha-se bem estabelecido que variações na natureza da energia refletida pela superfície que as circunda influenciam grandemente o número de afídios coleta$\operatorname{dos}(6,15)$.

O fato de a proporção de $M$. persicae ter sido, em relação ao total de espécies, bem maior na armadilha de água do que na de sucção (figura 3 ), pode ter resultado da grande atração dêste afídio pela côr amarela da armadilha de água (1, 8-10).

As médias mensais das temperaturas em Campinas, entre maio e setembro, nos anos de 1967 a 1969 , quando ocorreram as maiores migrações de Myzus persicae, estiveram entre $16^{\circ} \mathrm{C}$ e $20^{\circ} \mathrm{C}$, portanto bastante próximas das consideradas por Neitzel e Raueber (16) como mais favoráveis para o desenvolvimento do afídio. Êstes autores obtiveram ótimo desenvolvimento desta espécie em Brassica napus subspec. rapifera, nas temperaturas constantes de $20^{\circ} \mathrm{C}$ ou $23^{\circ} \mathrm{C}$, e verificaram ser de $30^{\circ} \mathrm{C}$ o limite superior em que uma pequena multiplicação do afídio ainda poderia ocorrer. Êles concluem que, em regiôes onde êste limite venha a ser atingido durante parte do dia, a temperatura pode ser o principal fator regulador da população do inseto. Isto poderia explicar o menor número de migrantes no ar, nos meses de verão, quando a temperatura poderá, eventualmente, até ultrapassar aquêle limite. A temperatura letal para êsse afídio, de $37,5^{\circ} \mathrm{C}$, determinada por Broadbent e Hollings (3), não foi atingida no periodo de observações.

A disponibilidade de boas hospedeiras, outro fator importante dentro do complexo de condições que regulam a população do afídio, pode também explicar algumas das variações observadas. E interessante lembrar que a maior incidência dos vírus dos amarelos (5) se dá nos meses mais frios do ano, vindo assim a coincidir com o período das maiores migrações do afídio vector IIyzus persicae.

As informações obtidas sôbre a migração de Myzus persicae poderão, eventualmente, constituir a base para a programação de épocas de plantio mais favoráveis, visando reduzir a incidência dos virus transmitidos por êste afídio para culturas eco- 
nômicas. Para tanto será necessário determinar, também, a proporção dos indivíduos da população de migrantes da espécie, encontrados naturalmente infectivos nas diferentes ocasiōes, já que em nenhuma semana dos três anos de observações sua migração foi totalmente interrompida. O acúmulo de tais dados poderá ser útil também para o eventual estabelecimento de um programa de previsão e alarme que oriente os agricultores nas ocasiōes que requeiram medidas especiais de proteção para as suas culturas, como os esquemas já em funcionamento em alguns países $(4,11$ e 17$)$.

SEAZONAL VARIATION OF Myzus persicae MIGRATIONS AT CAMPINAS, DURING THE YEARS OF 1967 TO 1969.

\section{SUMIMARY}

A study was made of the seazonal variations in the numbers of migrants of the aphid Myzus persicae (Sulzer) at Campinas, State of São Paulo, by sampling aerial populations from 1967 through 1969, with a suction trap and a yellow water trap. Weekly catches were recorded for both traps and summed up to give month totals.

Alate viviparous parthenogenetic females of Myzus persicae were caught every week of the years of 1967 to 1969 . This is an evidence that in the Campinas region $\left(22^{\circ} 50^{\prime} \mathrm{S}\right)$ there was no limiting factor to suppress parthenogenetic reproduction and inhibit flight during the period of observations. However, the trapping of males seems to indicate that an holocyclic multiplication of Myzus persicae may also exist. Where the oviparous female or other morphs of the species does also accur at Campinas, is not known.

The period when most of migration took place as revealed by samples taken by both traps occurred from May to september. The yellow water trap caught more Myzus persicae than the suction trap, but curves of annual distribution of alates trapped have the same shape. The ratio between the numbers of this aphid in the two types of traps remained rather constant, throughout two years, varying from 2.3 to 6.0 . This means that water trap catches were related to estimates of aerial density produced by the suction trap, a more precise apparatus for this determination, which does not exert attraction to the aphid species (20). Thus water trap may be used to the best advantage to collect Myzus persicae where an electricity supply to run the suction trap is lacking and / or when numbers of alate in the air are low. 
The proportion of Myzus persicae in relation to the total of species caught was also higher for the yellow water trap. In February, March, June, July and October of 1967 and June and July of 1968, 50\% of aphid species caught in the water trap were Myzus persicae. It represents $35 \%$ of total caught from May to October of 1969. In the suction trap the highest proportion of this species was $20 \%$ in June, 1968. This difference is attributed to the selective attractiveness of yellow color to aphia species.

\section{IITERATURA CITADA}

1. BROADBENT, L. Aphis migration and the efficiency of the trapping method. Ann. appl. Biol. 35:379-394, 1948.

2. — - The correlation of aphid numbers with the spread of leaf roll and rugose mosaic in potato crops. Ann. appl. Biol. $37: 58-65,1950$.

3. \& HOLLINGS, $M$. The influence of heat on some aphids. Ann. appl. Biol. 38:577-581, 1951.

4. CLOSE, R.; SMITH, H. C. \& LOWE, A. D. Cereal virus warning system. Commonw. phytopath. News 10:7-9, 1964.

5. Costa, A. S.; CARValho, anA MARIA B.; COSTA, C. L. \& NAGAI, H. Moléstias de vírus do tomateiro. Boletim do Campo 183:8-26, 1964.

6. COSTA, C. L. Nota prévia sôbre a redução da disseminação dos vírus de plantas, pelo efeito repelente de certas côres aos afídios vectores. Revta. Soc. bras. Fitopatologia 3:49-50, 1969.

7. —_. Ocorrência, no Estado de são Paulo, de forma sexuada de Myzus persicae, importante vector de vírus de plantas. Revta. Soc. bras. Fitopatologia 3:59-60, 1969.

8. EASTOP, V. F. Selection of aphid species by different kinds of insect traps. Nature, Lond. 176:936, 1955.

9. HEATHCOTE, G. D. The comparison of yellow cylindrical, flat and water traps, and of Johnson suction traps, for sampling aphids. Ann. appl. Biol. 45:133-139, 1957.

10. - - PALMER, J. M. P. \& TAYLOR, L. R. Sampling for aphids by traps and by crop inspection. Ann. appl. Biol. 63: 155-166, 1969.

11. HULL, R. The spray warning scheme for control of sugar beet yellows in England. Summary of results between 1959-66. Pl. Path. 17:1-10, 1968.

12. JOHNSON, C. G. A suction trap for small airbone insects which automatically segregates the catch into successive hourly samples. Ann. appl. Biol. 37:80-91, 1950.

13. LEWIS, T. The effects of an artificial windbreak on the aerial distribution of flying insects. Ann. appl. Biol. 55:503-512, 1965. 
14. MOERICKE, V. Eine Farbfalle zur Kontrolle des Fluges von Blattläusen insbesondere der Pfirsichblattlaus Myzodes persicae (Sulz.). NachrBl, dt. PflSchutzdienst, Stuttgart, 3:23-24, 1951.

15. ___._. Neue Untersuchungen über das Farbsehen der Homopteren. In: Proc. Sec. Conf. Potato Virus Diseases, Lisse-Wageningen, 1954. Wageningen, H. Veenman \& Zonen, 1955. p. 55-69.

16. NEITZEL, K. \& RAEUBER, A. Ökologische Untersuchungen an Aphiden. I. U̇ber die Temperaturverträglichkeit virginoparer Myzus persicae bei konstanten Temperaturen auf Kohlrüben. Ent. exp. \& appl. 11:115-132, 1968.

17. RIS LAMBERS, D. H. Potato aphids and virus diseases in the Netherlands. Ann. appl. Biol. 42:355-360, 1955.

18. STROYAN, H. L. G. Idenfication of aphids living on citrus. Pl. Prot. Bull. F.A.O. 9:45-65, 1961.

19. TAYLOR, L. R. An improved suction trap for insects. Ann. appl. Biol. 38:582-591, 1951.

20. - The absolute efficiency of insect suction traps. Ann. appl. Biol. 50:405-421, 1962. 